\title{
Effect of Cardiac Rehabilitation on Heart Rateand Functional Capacity in Patients After Myocardial Infarction
}

\author{
Mandana Parvand $^{1 *}$, Babak Goosheh ${ }^{2}$, Ali Reza Sarmadi ${ }^{1}$ \\ 1. Department of Physical Therapy, School of Medical Sciences, Tarbiat Modares University, Tehran, Iran. \\ 2. Department of Physiotherapy, University of Social Welfare \& Rehabilitation Sciences, Tehran, Iran
}

Cftation: Parvand M, Goosheh B, Sarmadi AR. Effect of Cardiac Rehabilitation on Heart Rate and Functional Capacity in Patients After Myocardial Infarction. Iranian Rehabilitation Journal. 2016; 14(3):157-162. https://doi.org/10.18869/nrip.irj.14.3.157

dof ${ }^{\text {s }}$ : https://doi.org/10.18869/nrip.irj.14.3.157

Article info:

Received: 24 Mar. 2016

Accepted: 11 Jul. 2016

\section{Keywords:}

Cardiac rehabilitation, Myocardial infarction, Functional capacity, Heart rate

\section{A B S T RACT}

Objectives: The primary purpose of this study was to determine the methods and means of prevention and treatment of coronary artery disease. In this study, we used a new regimen on heart rate and functional capacity of patients after myocardial infarction. This study also determines the effect of a new regimen on these factors.

Methods: The cross sectional study was designed to assess the clinical trials before and after intervention. The effect of our new regimen was assessed according to method of Bruce stress test. The values of heart rate and functional capacity before and after intervention were compared.

Results: The Bruce stress test revealed a significant increase in functional capacity of the participants. The criterion deviation in functional capacity variable was $13.19 \pm 2.242$ METS and 24.42 \pm 6.00 METS before and after the training sessions, respectively. A rise in the amount of METS (body oxygen survey at rest state equal to 3.5 milliliter oxygen to each $\mathrm{kg}$ person weight at minute) from secondary post test to primary test was observed $(\mathrm{P}<0.05)$. There was a decrease in heart rate after ten sessions of training. The criterion deviation and average of the heart rate variable was $83.30 \pm 11.71$ and $81.60 \pm 13.45$ before and after the sessions, respectively $(\mathrm{P}<0.05)$.

Discussion: Cardiac rehabilitation can increase the performance of blood circulation and uptake of oxygen in body. Due to these changes, there was a significant increase in the functional capacity and an insignificant reduction in the heart rate.

\section{Introduction}

he only known treatment for myocardial infarction (MI) was complete bed rest for several weeks and reduced physical activity for several months [1-3]. Cardiac reha- bilitation based on exercise training reduces the effects of deconditioning of bed rest and delays the consequences of chest angina, chronic heart failure (CHF), and MI [1$3,12-14]$. The barriers of cardiac rehabilitation should be considered [20].

* Corresponding Author:

Mandana Parvand, MA

Address: Department of Physical Therapy, School of Medical Sciences, Tarbiat Modares University, Tehran, Iran.

Tel: +98 (912) 2393357

E-mail:parvandmn@yahoo.com 
Exercise training is the base of cardiac rehabilitation, which also includes psychological counseling and nutrition regimen $[4,12,18,19]$. It can help increase functional capacity (FC) and reduce cardiac ischemia, chest angina, and heart rate [6].

Although Low-level Sub max Heart Rate exercise regimens were originally developed to assess their positive [7-10, 15, 18], they have been extensively used to study heart failure, MI, CABG (Coronary Artery Bypass Graft) patients, and other cardiovascular conditions. It has been observed that these regimens can increase blood flow by increasing the Vascular Endothelial Growth Factor-A (VEGF) factor in blood [11]. In this study, we assessed the effect of a new regimen based on low level sub max heart.rate exercise on MI patients. The purpose of this study was to assess the effects of this regimen on the heart rate and $\mathrm{FC}$ of post-MI patients.

\section{Methods}

This study was performed on 40 patients (aged 5065 years) with MI by clinical experience method after taking their well-informed consent. These people were selected randomly from the available database of Heart and Veins Unit of Modares Hospital of Tehran and Pooya Rehabilitation Center.

The inclusion criteria for choosing subjects for the research are as follows: lack of presence of extensive variations in heart rate and ECG, ejection fraction above 35\% (contractile ratio), a gap of 4 weeks after the occurrence of last MI, and should be a heart rehab candidate in the doctor's view. Patients having a blood pressure loss less than 20 millimeter mercury or blood pressure rise more than 220/120 mm mercury were excluded. Patients having headaches, vertigo, ataxia, extensive paleness, nausea ST piece premature variations and other variations in ECG (as ventricular improper waves, PVC, etc.) and those with extensive arrhythmias were also not included in the study.

An exercise stage with slope and speed variations of $1 \%$ rise in slope and $1 \mathrm{~km} / \mathrm{h}$ in speed for arriving at the patient's THR (each process duration from exercise was 5 minutes); a recovery process that includes $7.2 \%$ slope and $1 \mathrm{~km} / \mathrm{h}$ speed; and finally rest. The patients were put under 10 sessions of heart rehabilitation exercises regimen, as mentioned above. THR for the first 5 sessions was calculated as $65 \%$ maximum heart rate, and for the last 5 sessions, it was $70 \%$ maximum heart rate.

After completing the heart rehabilitation sessions, the patient's heart rate and FC were evaluated based on
Bruce stress test method. The patient Target Heart Rate (THR) was calculated using 65\% Max. H. Rate formula. The Esaote biomed model and headset, lit man master model, and $\mathrm{ALpk}_{2}$ model pointer metal pressure gauge device based on Bruce sport test method were used to help the patients achieve their THR.

Pair t-test was used for analyzing the information in the normal data distribution. The two exceptional cases of variables that had abnormal distribution were analyzed using Wilcoxon Method. In this study, P-value was less than $5 \%$ was considered to be significant, and SPSS Software was used for analyzing the data.

\section{Results}

Of the 40 studied patients, 28 were males and 12 were females. Their average age was 57 years, 7 months, and 7 days. The average delay duration was 25 days at the beginning of the treatment. The least and the most delay amounts were 15 and 30 days, respectively.

The METS scale (body oxygen survey at rest state equal to 3.5 milliliter oxygen to each $\mathrm{kg}$ person weight at minute) was used for reviewing the FC variable. Arrange and criterion deviations of the $\mathrm{FC}$ variable were $13.19 \pm 2.242$ and $24.42 \pm 6.00$ before and after the heart rehabilitation sessions, respectively. A significant rise in the value of METS from secondary post test to primary one with a $\mathrm{P}<0.05$ was w level exerc observed (Figure 1). Finally, the criterion deviation and average of the heart rate variable were found to be $83.30 \pm 11.71$ and $81.60 \pm 13.45$ before and after the heart rehabilitation sessions, respectively. (Figure 2).

\section{Discussion}

In this study, a significant rise was observed in FC on the METS scale. This rise signifies an improvement in muscular performance, resulting in increased oxygen uptake in the body. There are several other studies about the effect of low-level exercise regimen using METS scale on cardiac patients.

Sullivan et al. [8] believed that patients after MI have low output, and thus, a high intake of $\mathrm{O}_{2}$ due to a highlevel exercise regimen will cause more harm than good. It is for this particular reason that low-level exercise regimen is recommended to increase FC. On the contrary, Haitsma et al. [9] reported that post-MI pigs when subjected to a high-level exercise regimen (Max Heart Rate $>85 \%$ ) did not have any ischemic disorders. They also found that with decreased oxygen uptake, the output and perfusion of muscles will be low. 


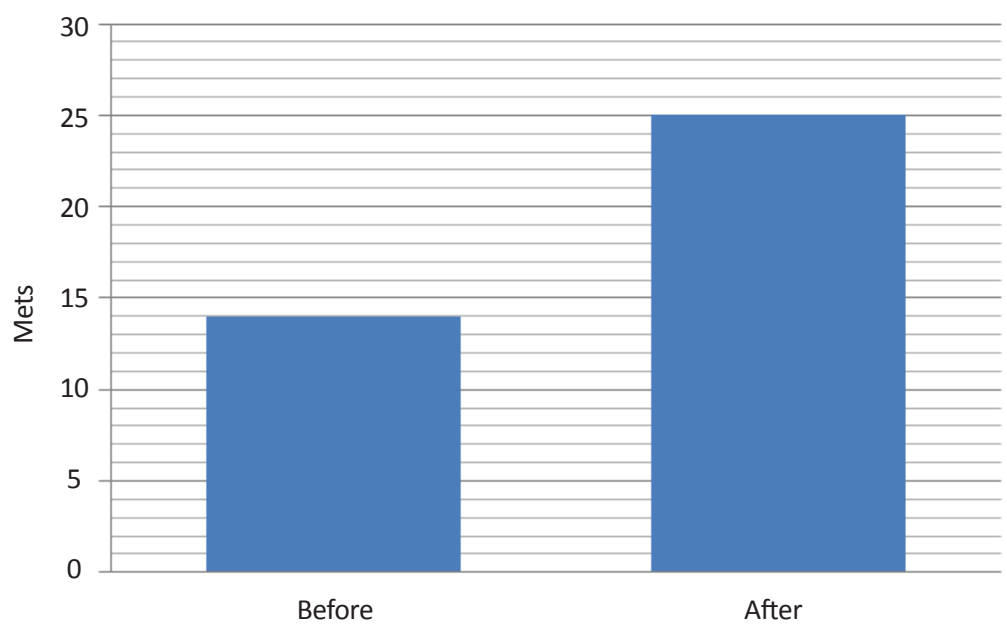

Iranian Riehabilitation \ournal

Figure 1. Review of FC variations of patients based on METS scale before and after heart rehabilitation regimen.

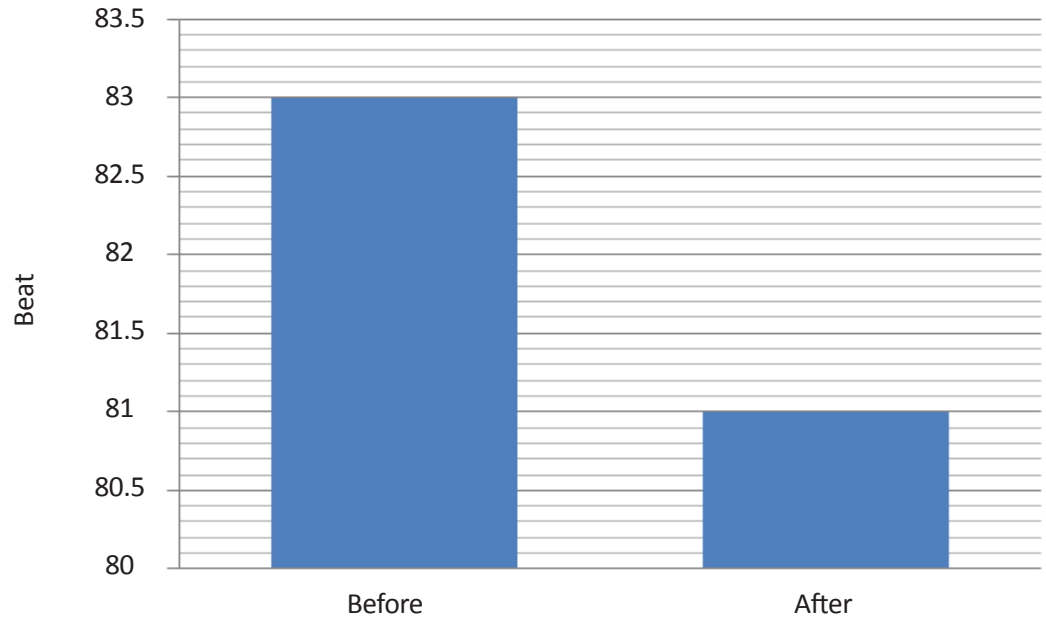

Figure 2. Review of heart rate variations of patients before and after the heart rehabilitation.

Ilranian Rehabilitation Journal

On the other hand, Nieuwland et al. [10, 19] found that the ventilation of air threshold (VAT) will increase more in patients following low-level exercise regimen with high frequency will increase more than in patients with lowlevel exercise regimen with low frequency. However, they reported that the amount of peak $\mathrm{O}_{2}$ in both groups of patients ( $60 \%$ to $70 \%$ Reserve Heart Rate) will be the same.

Therefore, low-level exercise regimen with high frequency is recommended to increase FC. Post-MI patients who undergo high frequency regimen sustain longer in the stress test because they have less lactate in their blood due to the rise in VAT. Other reasons for their good performance are the increase in the strength of muscles and better performance of motor skill.

We found that a low-level exercise regimen needs to be prescribed to the patients to significantly increase their
FC during treatment. Afify et al. [11] reported that compared to the low-frequency regimen, the high-frequency regimen has a greater impact on hemodynamic of coronary artery disease $(\mathrm{CAD})$ patients. They observed that a high-frequency regimen effectively increases FC, quality of life, and blood pressure.

On the other hand, Nieuwland et al. [10, 19] believed that only high frequency exercise can improve heart rate and blood pressure. Since in this research, we used a low-frequency exercise regimen, we observed an insignificant decrease in the heart rate during the rest state.

\section{Conclusion}

Cardiac rehabilitation is a long drawn process involving expensive equipments. The regimen effectively increases FC and improves many hemodynamic factors 
like blood pressure and heart rate. Due to the positive effect of this regimen on the quality of life for CAD patients, we recommend a routine medical or physical therapy treatment to post-MI patients under the supervision of professional doctors, cardiac rehab physiotherapists, and nurses. We also suggest the requirement of further researches in the area of cardiac rehab regimen involving high intensity and high frequency.

\section{Key message}

What is already known on these topics?

Several studies have reported an association between cardiac rehabilitation and an increase in $\mathrm{FC}$, a decrease in blood pressure and heart rate, and improvement in the quality of life in post-MI patients.

Low scores on Bruce stress test explain the loss of FC and quality of life in patients after MI, suggesting that the patients are at risk for impaired mobility.

The positive effect of this new regimen of cardiac rehab opens a new window of life for the post-MI patients.

What this study adds?

This study analyzes the clinical characteristics and physical performance measures related to Bruce stress test as an alternative method to explain the increase in FC. It also demonstrates that after cardiac rehabilitation using the proposed regimen significantly increases FC.

\section{Acknowledgments}

The current research hasn't received any financial support.

\section{Conflict of Interest}

The authors declared no conflict of interests.

\section{References}

[1] Thompson PD, Braunwald, S. Exercise-based, comprehensive cardiac rehabilitation. In: Eugene Braunwald MD, editor Heart Disease Text Book of Cardiovascular Medicine. Philadelphia: Elsevier Saunders; 2012, p. 1036-041.

[2] Jensen L, Pilegaard H, Neufer PD, Hellsten Y. Effect of acute exercise and exercise training on VEGF splice variants in human skeletal muscle. American Journal of Physiology-
Regulatory, Integrative \& Comparative Physiology. 2004; 287(2):397-402. doi: 10.1152/ajpregu.00071.2004

[3] Saltin B, Gollnick PD. Skeletal muscle adaptability: Significance for metabolism and performance. Comprehensive Physiology. 1983. doi: 10.1002/cphy.cp100119

[4] Sundberg CJ. Exercise and training during graded leg ischaemia in healthy man with special reference to effects on skeletal muscle. Acta Physiologica Scandinavica. 1993; 615:150. PMID: 8140900

[5] Yang HT, Ogilvie RW, Terjung RL. Low-intensity training produces muscle adaptations in rats with femoral artery stenosis. Journal of Applied Physiology. 1991; 71(5):1822-9.

[6] Gustafsson T, Puntschart A, Kaijser L, Jansson E, Sundberg CJ. Exercise-induced expression of angiogenesis-related transcription and growth factors in human skeletal muscle. American Journal of Physiology-Heart and Circulatory Physiology. 1999; 276(2):679-85. PMID: 9950871

[7] Sullivan M, McKirnan MD. Errors in predicting functional capacity for postmyocardial infarction patients using a modified Bruce protocol. American Heart Journal. 1984; 107(3):48692. PMID: 6695692

[8] Haitsma DB, Bac D, Raja N, Boomsma F, Verdouw PD, Duncker DJ. Minimal impairment of myocardial blood flow responses to exercise in the remodeled left ventricle early after myocardial infarction, despite significant hemodynamic and neurohumoral alterations. Cardiovascular Research. 2001; 52(3):417-28. doi: 10.1016/s0008-6363(01)00426-6

[9] Nieuwland W, Berkhuysen MA, van Veldhuisen DJ, Brügemann J, Landsman ML, van Sonderen E, et al. Differential effects of high-frequency versus low-frequency exercise training in rehabilitation of patients with coronary artery disease. Journal of the American College of Cardiology. 2000; 36(1):202-7. PMID: 10898435

[10] El-Tantawy RM, Mounir EM. Evaluation of high versus low frequency cardiac rehabilitation programs in patients with coronary artery disease. Egyptian Heart Journal. 2008, 60(3):213-221.

[11] Frown FD, Dean E. Cardiovascular and pulmonary physical therapy; Evidence and practice. Philadelphia: Mosby; 2006.

[12] Redwood DR, Rosing DR, Epstein SE. Circulatory and symptomatic effects of physical training in patients with coronary-artery disease and angina pectoris. New England Journal of Medicine. 1972; 286(18):959-65. doi: 10.1056/ NEJM197205042861801

[13] Detry JM, Rousseau M, Vandenbroucke G, Kusumi F, Brasseur LA, Bruce RA. Increased arteriovenous oxygen difference after physical training in coronary heart disease. Circulation. 2005; 44(1):109-18. PMID: 5561413

[14] Ades PA. Cardiac rehabilitation and secondary prevention of coronary heart disease. New England Journal of Medicine. 2001; 345(12):892-902. doi: 10.1056/NEJMra001529

[15] Thompson PD. Exercise prescription and proscription for patients with coronary artery disease. Circulation. 2005; 112(15):2354-363. doi: 10.1161/circulationaha.104.502591 
[16] Ades PA,Coello CE: Effect of exercise and cardiac rehabilitation on cardiovascular outcome. Medical Clinics of North America. 2000; 84(1):251-65. PMID: 10685138

[17] Lavie CJ, Milani RV. Effects of cardiac rehabilitation programs on exercise capacity, coronary risk factors, behavioral characteristics, and qualify of life in a large elderly cohort. American Journal of Cardiology. 1995; 76(3):177-79. doi: 10.1016/s0002-9149(99)80054-x

[18] Taylor RS, Brown A, Ebrahim S, Jolliffe J, Noorani H, Rees $\mathrm{K}$, et al. Exercise-based rehabilitation for patients with coronary heart disease: systematic review and meta-analysis of randomized controlled trials. American Journal of Medicine. 2004; 116(10):682-92. doi: 10.1016/j.amjmed.2004.01.009

[19] Berkhuysen MA, Nieuwland W, Buunk BP, Sanderman R, Viersma JW, Rispens P. Effect of high versus low frequency exercise training in multidisciplinary cardiac rehabilitation on health-related quality of life. Journal of Cardiopulmonary Rehabilitation. 1999; 19(1):22-28. PMID: 10079417

[20] Afrasiabi-Far A, Hosseini P, Fallahi-Khoshknab M, Yaghmaei $F$. [The barriers to myocardial infarction patients' participation in cardiac rehabilitation program (Persian)]. Journal of Rehabilitation. 2008; 9(3-4):75-99. 
